\title{
KINETIC STUDY OF SILVER (I) OXIDE LAYER ELECTROREDUCTION
}

\author{
J. Gómez Becerra, R. Salvarezza and A. J. Arvia
}

Instituto de Investigaciones Fisicoquimicas Teóricas y Aplicadas (INIFTA), Facultad de Ciencias Exactas, Universidad Nacional de La Plata, Sucursal 4, Casilla de Correo 16, (1900) La Plata, Argentina

(Received 15 May 1989)

\begin{abstract}
The potentiostatic electroreduction of silver (I) oxide layer has been investigated in $0.1 \mathrm{M} \mathrm{NaOH}$. The study was complemented by electroreduced silver surface characterisation through scanning electron microscopy micrographs and thallium UPD voltammetry. By properly adjusting the electroreduction conditions three well-defined processes could be distinguished: (i) the electroreduction of the $\operatorname{Ag}_{2} \mathrm{O}$ monolayer in direct contact with the silver substrate which involves a current decay following a first order law; (ii) the electroreduction of the primary $\mathrm{Ag}_{2} \mathrm{O}$ layer which can be described through an instantaneous nucleation and 3-D growth mechanism under diffusion control; (iii) the electroreduction of the secondary $\mathrm{Ag}_{2} \mathrm{O}$ layer involving a nucleation and 3-D conical growth under charge transfer control and a correction term for the death of growing nuclei. SEM and thallium UPD results correlate, in principle, with the conclusions derived from the electrochemical data.
\end{abstract}

\section{INTRODUCTION}

The electrooxidation of silver to $\operatorname{Ag}(\mathrm{I})$ species in alkaline solutions is a complex reaction involving several stages. According to the literature the first stage yields a $\mathrm{AgOH}$ monolayer[1], upon which the growth of a basal inner $\mathrm{Ag}(\mathrm{I})$ oxide layer (primary layer) and the simultaneous formation of soluble $\mathrm{Ag}(\mathrm{I})$ species take place[2]. Subsequently, an outer $\mathrm{Ag}(\mathrm{I})$ oxide layer (secondary layer) is produced through a nucleation and 3-D growth mechanism under a diffusion control which is related to the transport of $\mathrm{Ag}(\mathrm{I})$ ions through the entire $\operatorname{Ag}(\mathrm{I})$ oxide layer[3]. The secondary layer appears to be more porous and its water content is also greater than that of the primary layer[2] due to the presence of small crystals and voids $[4,5]$.

The voltammetric electroreduction of the $\mathrm{Ag}(\mathrm{I})$ oxide layer usually displays a single sharp cathodic peak, which can be split into two peaks by carefully choosing the experimental conditions. This depends on both the electroreduction potential programme and the anodization time involved in the formation of the $\mathrm{Ag}(\mathrm{I})$ oxide layer[6]. The electroreduction process has been reported as a first order reaction involving two electrons, and a transfer coefficient equal to 0.71 $\pm 0.03[7]$. Other voltammetric results indicate linear dependences of the height of the electroreduction peak on the square root of the potential sweep rate, $v$, with two different slopes one equal to $16 \mathrm{~mA} \mathrm{~s} \mathrm{~s}^{1 / 2} \mathrm{mV}^{-1 / 2}$ for $v<55 \mathrm{mV} \mathrm{s}^{-1}$, and another one equal to $6 \mathrm{~mA} \mathrm{~s}^{1 / 2} \mathrm{mV}^{-1 / 2}$ for $v>55 \mathrm{mV} \mathrm{s}^{-1}$ [8]. These results were also confirmed in $1 \mathrm{M} \mathrm{NaOH}$ for $v<50 \mathrm{mV} \mathrm{s}^{-1}$ and, in this case a lineal voltammetric electroreduction peak potential $v s \log v$ plot was found[9]. The galvanostatic data reported in the literature [9] at different temperatures, however, exhibit abrupt peaked potential values which are difficult to reconcile with conventional electrochemical kinetic mechanisms, except through an interpretation based upon the nuclea- tion and growth of new phases[10]. Thus, the $\mathrm{Ag}(\mathrm{I})$ oxide layer electroreduction in $1 \mathrm{M} \mathrm{NaOH}$ was considered as a progressive nucleation and 2-D growth under charge transfer control on the basis of potentiostatic electroreduction current transient analysis[11], and SEM imaging[12]. The potentiostatic current transients related to the electroreduction of $\mathrm{Ag}(\mathrm{I})$ oxide layers were also described in terms of Kolmogoroff-Avrami equation for phase change[13-15]. The interpretation of these results favoured a nucleation and 3-D growth process under diffusion control, ie the growth of the nucleous radius was directly proportional to $t^{1 / 2}$, where $t$ is the time of the experiment.

It seems rather unrealistic to draw definite mechanistic conclusion for the electroreduction of $\mathrm{Ag}(\mathrm{I})$ oxide layers exclusively from voltammetric data. The corresponding voltammetric peak current height, $j_{\mathrm{p}}$, follows either $j_{\mathrm{p}} v s v$ or $j_{\mathrm{p}} v s v^{1 / 2}$ linear relationships. These parametric functionalities are determined by the ranges of both $v$ and $\mathrm{Ag}(\mathrm{I})$ oxide charge covered by the experiments[16]. In addition, the potentiostatic electroreduction current transients depend also considerably on the proper history of the Ag(I) oxide layer preceding its electroreduction. These results suggested the possibility that different reaction paths acting in parallel participate in the electroreduction process.

Recently, the Ag(I) oxide layer electroformation and electroreduction processes were followed by applying a quartz microbalance technique[17] during voltammetric experiments in $0.1 \mathrm{M} \mathrm{NaClO}_{4}+0.01 \mathrm{M}$ $\mathrm{NaOH}$, at $20 \mathrm{mV} \mathrm{s}^{-1}$. Curiously, it was observed that the topography of the $\mathrm{Ag}(\mathrm{I})$ oxide layer, and that of the electroreduced silver layer changed for a certain time after the faradaic processes had ceased. This fact is consistent with a metal surface reconstruction process involving surface diffusion of atoms, a type of process which has already been described for several electrochemical formations of new phases $[18,19]$. Its occurrence is related to the fact that the thermodynamic 
equilibrium of the system[20] has been attained at the end of the proper phase change process. As examples related to this type of process one has the change in the surface structure of silver overlayers produced either through voltammetric cycling[21-23], or by potential holding at the oxide layer region, or by using different surface preparation techniques. It should also be noted that a strong dependence of the surface structure of silver resulting from the electroreduction of thick silver oxides on the electroreduction procedure has been observed[18]. The UPD of thallium on silver layers allows to obtain in a rather simple and direct way information about the crystalline domains of the substrate[21].

The present work is devoted to the investigation of the complex mechanism of $\mathrm{Ag}(\mathrm{I})$ oxide layers electroreduction. In this case, the $\mathbf{A g}(\mathbf{I})$ oxide layers have been prepared under well controlled conditions in order to make sensible comparisons possible. Attempts are also made for the first time to separate the different contributions to the overall electroreduction reaction, and to relate them to the complex structure of the Ag(I) oxide layer. The latter can be made by properly selecting the characteristics of the potential programme for the reaction. Finally, a correlation between the structure of the electroreduced silver and the electroreduction conditions is established.

\section{EXPERIMENTAL}

The working electrodes were made of polycrystalline (pc) $\mathrm{Ag}(99.99 \%)$ rods axially embedded in Araldite cylindrical holders to obtain circular silver exposed areas of $0.05 \mathrm{~cm}^{2}$ geometric area.

The working electrodes were mechanically polished starting from fine grained emery paper and followed with alumina paste of $1 \mu \mathrm{m}$ dia. to obtain mirror-like metal surfaces. Before the electrochemical measurements the electrodes were degreased with alcohol and rinsed with triply distilled water. Special care was taken to avoid crevices between the silver rod and the Araldite holder which could lead to artifacts in the electrochemical measurements[24]. The counter electrode was a large $\mathrm{Pt}$ sheet placed into a separate cell compartment. A saturated calomel electrode (sce), $E^{\circ}$ (vs she $)=0.242 \mathrm{~V}$, connected through a Luggin-Haber capillary tip was used as reference electrode, and potentials in the text are given to the sce scale. The electrolyte solution, $0.1 \mathrm{M} \mathrm{NaOH}$, was prepared from analytical grade (Merck, p.a.) reagent and triply distilled water. Solutions were bubbled with purified $\mathrm{N}_{2}$ gas for $3 \mathrm{~h}$ prior to the electrochemical measurements. The latter were made at $25^{\circ} \mathrm{C}$. Cathodic current transients at constant potential were obtained by applying conventional potential step programmes as described later on in the text, for 90 and $300 \mathrm{~s}$, after a previous potential step at $E_{\mathrm{s}, \mathrm{c}}=-1.2 \mathrm{~V}$ for $60 \mathrm{~s}$, followed by stepping the potential to $E_{\mathrm{s}, \mathrm{a}}=0.45 \mathrm{~V}$ in order to ensure the reproducible electroformation the $\mathrm{Ag}(\mathrm{I})$ oxide layer.

Scanning electron microscopy (SEM) was used to characterize the topography of the silver surfaces formed under the different electroreduction conditions. Voltammetric experiments of thallium UPD on the silver surfaces were also performed in $1 \times 10^{-3}$ $\mathrm{Tl}_{2} \mathrm{SO}_{4}+0.1 \mathrm{M} \mathrm{HClO}_{4}$ with similar intentions.

\section{RESULTS}

\section{Voltammetric data}

A single triangular potential sweep voltammogram of a pc Ag electrode run at $5 \times 10^{-4} \mathrm{~V} \mathrm{~s}^{-1}$ between $E_{\mathrm{c}}$ $=-0.20 \mathrm{~V}$ and $E_{\mathrm{a}}=0.45 \mathrm{~V}$, in $0.1 \mathrm{M} \mathrm{NaOH}$ (Fig. 1), exhibits three anodic current plateau, $A_{1 \mathrm{~m}}$ at $0.165 \mathrm{~V}$ and current peaks $A_{1}^{\prime}$ at $0.21 \mathrm{~V}$ and $\mathrm{A}_{1}^{\prime \prime}$ at $0.28 \mathrm{~V}$, and one single sharp cathodic peak $C_{1}$ at $0.1 \mathrm{~V}$. The voltammogram becomes insensitive to solution stirring. Peak $A_{1 m}$ which can be better displayed at higher $v$ as already reported elsewhere[3], involves a charge density of about $0.4 \mathrm{mC} \mathrm{cm}^{-2}$, and is associated with the formation of the $\mathrm{AgOH}$ monolayer[1]. Peak $A_{1}^{\prime}$ is related to the formation of the primary layer[3], and to the simultaneous base silver electrodissolution[2], whereas peak $A_{1}^{\prime \prime}$ corresponds to the formation of the secondary layer. The latter process involves a nucleation and 3-D growth

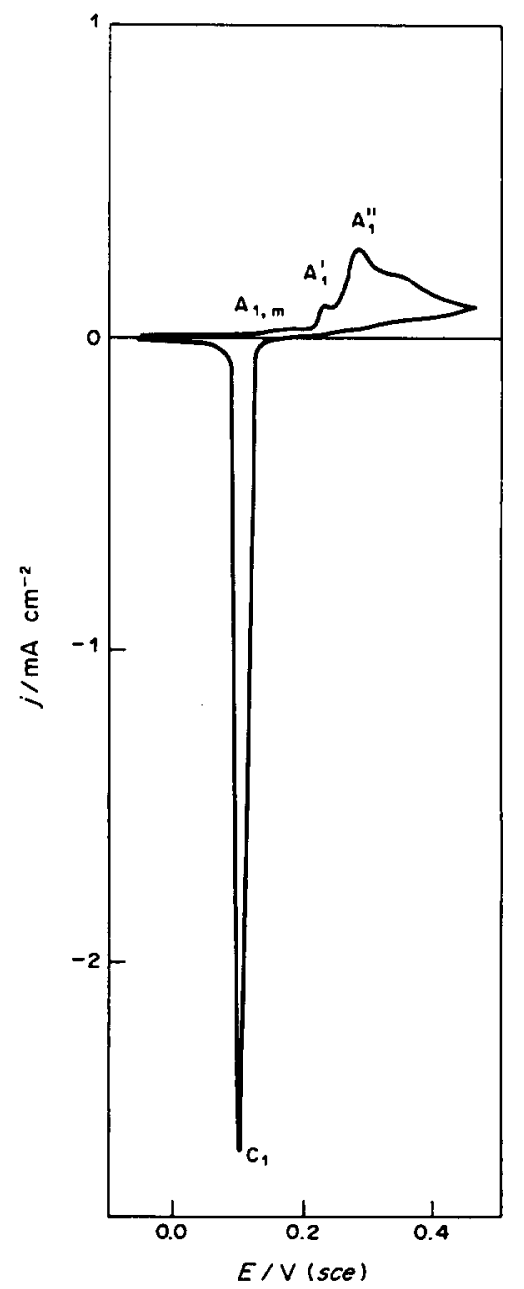

Fig. 1. Voltammogram of a Ag electrode immersed in $0.1 \mathrm{M}$ $\mathrm{NaOH}$ run at $5 \times 10^{-4} \mathrm{~V} \mathrm{~s}^{-1}$ between $E_{\mathrm{c}}=-0.20 \mathrm{~V}$ and $E_{\mathrm{a}}$ $=0.45 \mathrm{~V}, 25^{\circ} \mathrm{C}$ 
mechanism [5] controlled by the diffusion of $\mathrm{Ag}(\mathrm{I})$ ions through the Ag(I) oxide layer[3].

The voltammetric electroreduction of $\mathrm{Ag}(\mathrm{I})$ oxide layers formed by means of a linear potential sweep up to $E_{\mathrm{a}}=0.4 \mathrm{~V}$ has been considered. The electroreduction reaction yields a silver layer and it is characterised by either a single cathodic current peak (peak $C_{1}$ in Fig. 1) or a multiplicity of cathodic peaks (peaks $C_{1}^{\prime}$ and $C_{1}^{\prime \prime}$ in Fig. 2). For instance, the results shown in Fig. 2 correspond to the voltammetric electroreduction of $\mathrm{Ag}(\mathrm{I})$ oxide layers produced for different growing times $\tau_{\mathrm{a}}$, at the constant potential $E_{\mathrm{a}}=0.30 \mathrm{~V}$. Thus, for small values of $\tau_{a}$ peak $C_{1}^{\prime}$ becomes predominant, but as $\tau_{\mathrm{a}}$ increases, then peak $C_{1}^{\prime \prime}$ emerges and becomes relatively more important than peak $C_{1}^{\prime}$. The silver layer resulting from the voltammetric electroreduction appears to be a reformed silver layer constituted by a large number of electrodeposited silver nodules[10].

\section{Potentiostatic current transients}

The general procedure used for these runs consisted in precathodising the polished pc silver electrode immersed in $0.1 \mathrm{M} \mathrm{NaOH}$ at $E_{\mathrm{c}}=-1.2 \mathrm{~V}$ during $60 \mathrm{~s}$, to achieve a reproducible initial electroreduced metal surface, and subsequently, in stepping the potential to $0.45 \mathrm{~V}$ for $\tau_{\mathrm{a}}=300 \mathrm{~s}$ to form the $\mathrm{Ag}(\mathrm{I})$ oxide layer. Under these conditions a reproducible amount of $\mathrm{Ag}(\mathrm{I})$ oxide of well defined characteristics[3] became the starting material for the electroreduction process. The latter proceeded at a constant potential $E_{\mathrm{s}}$ $\left(0.100>E_{\mathrm{s}}>0.127 \mathrm{~V}\right)$, immediately after the $\mathrm{Ag}(\mathrm{I}) \mathrm{ox}-$ ide layer formation. Simultaneously, the cathodic current transient related to each $E_{\mathrm{s}}$ value was recorded (Fig. 3). The potentiostatic current transients exhibit at least two processes, one $\left(R_{1}\right)$ in the short time range, and another one $\left(R_{2}\right)$ in the long time range. The current transient for each process displays a typical current maximum, as it often happens for the nucleation and growth of new phases in electrochemical systems. The process $R_{1}$ which can be observed in the first few seconds, involves a relatively small charge density, $q_{\mathrm{R} 1}$. The corresponding current maximum, $I_{\mathrm{M} 1}$, appears at the time, $t_{\mathrm{M} 1}$, and both $I_{\mathrm{M} 1}$ and $t_{\mathrm{M} 1}$ become scarcely sensitive to changes in $E_{\mathrm{s}}$. In contrast, the process $R_{2}$ involves a relatively large charge density value, $q_{\mathrm{R} 2}$, which is about $38 \mathrm{mC} \mathrm{cm}^{-2}$, and the corresponding $I_{\mathrm{M}, 2}$ and $t_{\mathrm{M}, 2}$ values both change considerably with $E_{\mathrm{s}}$. Therefore, the separation of processes $R_{1}$ and $R_{2}$ becomes possible by properly selecting the electroreduction conditions. Thereby, on the basis of voltammetry data (Fig. 2), processes $R_{1}$ and $R_{2}$ can be related as reported elsewhere [1-3] to the electroreduction of the primary and the secondary layer, respectively.

The electroreduction process $R_{1}$. In order to enhance the contribution of the electroreduction process $\mathrm{R}_{1}$ the $\mathbf{A g}(\mathrm{I})$ oxide layer was prepared by applying the perturbing potential programme depicted as an inset in Fig. 4, by setting $\tau_{\mathrm{a}}=90 \mathrm{~s}$. This new experimental procedure yields a better separation of the current transients for the different processes within the $0.125<E_{\mathrm{s}}<0.140 \mathrm{~V}$ range. In this way the electroreduction potential step can be adjusted to observe the

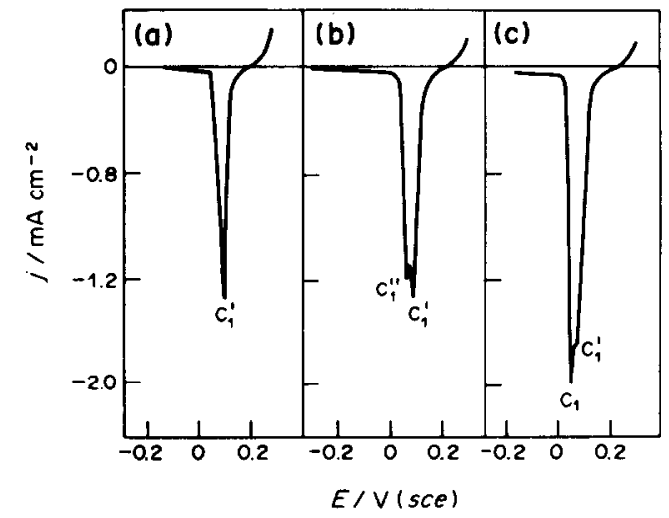

Fig. 2. Single potential scan voltammograms run at $5 \times$ $10^{-3} \mathrm{~V} \mathrm{~s}^{-1}$ from $E_{3}=0.30 \mathrm{~V}$ downwards, after different potential holding times at $E_{\mathrm{a}}=0.30 \mathrm{~V}: \tau_{\mathrm{s}}=$ (a) 2 ; (b) $5 ;$ (c) $10 \mathrm{~s}$ $25^{\circ} \mathrm{C}$.

complete electroreduction process $R_{1}$ without any appreciable interference of process $R_{2}$ (Fig. 4). Then, the corresponding current transients exhibit an initial decrease in the $0-0.5 \mathrm{~s}$ interval, followed by the current increase to reach the $I_{\mathrm{M}_{1}}$ value, and finally a smooth current decrease to attain a limiting current value for $t \rightarrow \infty$. These current transients become independent of the solution stirring, but the value of $I_{M 1}$ and the characteristics of the decaying current depend slightly on $E_{\mathbf{s}}$. The decreasing current transient portions after $I_{\mathrm{M} 1}$, fit linear $I$ vs $t^{-1 / 2}$ plots (Fig. 5), the slope $\mathrm{P}_{1}$ of these lines being a function of the $E_{\mathrm{s}}$ value (Fig. 6).

The initial falling current involving a small charge density value, $q_{\mathrm{m}} \cong 0.05-0.1 \mathrm{mC} \mathrm{cm}^{-2}$, fits an exponential decay law. This fact suggests that the initial process corresponds to the electroreduction of $\mathrm{a} \mathrm{Ag}_{2} \mathrm{O}$ monolayer in direct contact with the silver substrate (Fig. 7).

The electroreduction process $R_{2}$. Let us consider again results depicted in Fig. 3. Process $R_{2}$ comprises most of the $A g(I)$ oxide electroreduction charge $\left(30-40 \mathrm{mC} \mathrm{cm}^{-2}\right)$. The shape of the current transients associated with process $R_{2}$ suggests that the kinetics of the reaction is likely determined by a nucleation and 3$\mathrm{D}$ growth mechanism. On the other hand, as $E_{\mathrm{s}}$ is diminished, a remarkable decrease in the value of $t_{\mathrm{M} 2}$ and correspondingly, a strong increase in that of $I_{\mathrm{M}_{2}}$ can be observed. The $E_{\mathrm{s}} v s \log j_{\mathrm{M} 2}$ plot at low values of $E_{\mathrm{s}}$ approaches a linear relationship with a slope close to $0.06 \mathrm{~V} \mathrm{dec}^{-1}$ (Fig. 8). These facts suggest that $\mathrm{R}_{2}$ can be related to a nucleation and growth process under charge transfer control. Accordingly, the $j v s t^{3}$ and the $j v s t^{2}$ straight line plots for $E_{\mathrm{s}}<0.125 \mathrm{~V}$ and $E_{\mathrm{s}}>0.125 \mathrm{~V}$, respectively (Figs $9 \mathrm{a}$ and b) are obtained, as predicted by well established reaction models[10].

Characteristics of the silver layer resulting from the silver oxide layer electroreduction

The topography of the silver layers resulting from the $\operatorname{Ag}(\mathrm{I})$ oxide layer electroreduction were followed through both SEM micrographs and voltammetric features of thallium UPD. The latter were directly 


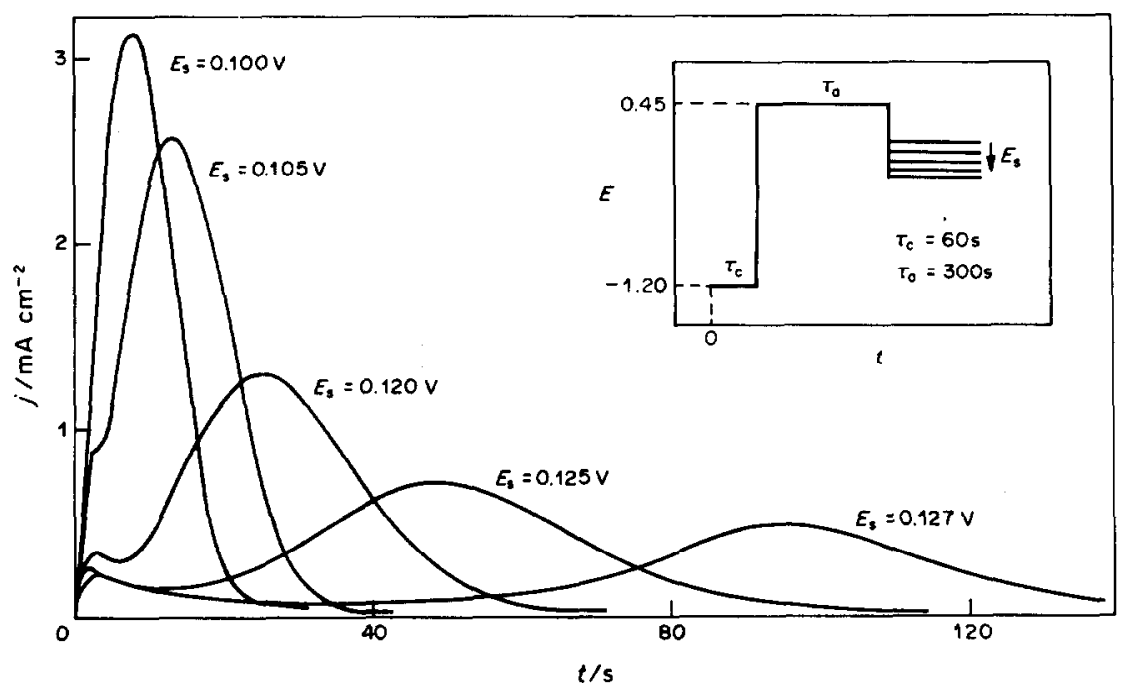

Fig. 3. Current transients related to $\mathrm{Ag}_{2} \mathrm{O}$ layer electroreduction run at different $\mathrm{E}_{\mathrm{g}}$ values. $25^{\circ} \mathrm{C}$. The $\mathrm{Ag}(\mathbf{l})$ oxide layer was previously formed according to the potential programme indicated at the inset, with the following values: $E_{\mathrm{c}}=-1.2 \mathrm{~V} ; \tau_{\mathrm{c}}=60 \mathrm{~s} ; E_{\mathrm{a}}=0.45 \mathrm{~V} ; \tau_{\mathrm{a}}=300 \mathrm{~s}$.

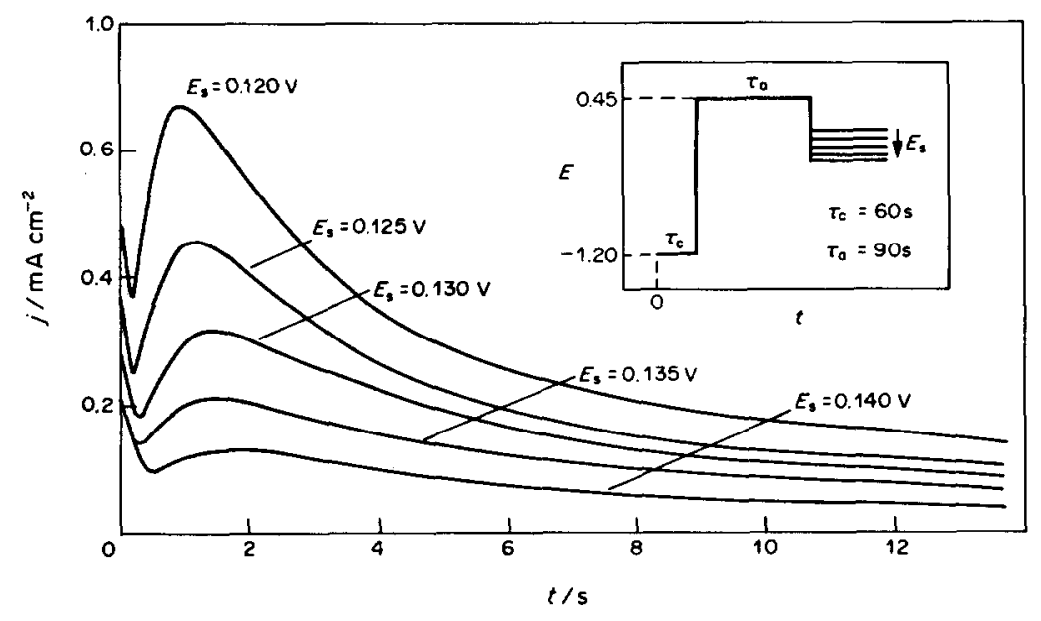

Fig. 4. Current transients related to the $\mathrm{Ag}_{2} \mathrm{O}$ oxide layer electroreduction run at different $E_{\mathrm{s}}$ values. $25^{\circ} \mathrm{C}$. The Ag(I) oxide layer was previously formed according to the potential programme indicated at the inset, with the following values: $E_{\mathrm{c}}=-1.2 \mathrm{~V} ; \tau_{\mathrm{c}}=60 \mathrm{~s} ; E_{\mathrm{a}}=0.45 \mathrm{~V} ; \tau_{\mathrm{a}}=90 \mathrm{~s}$. The portions of the current transients shown in the figure are related to the process denoted as $R_{1}$ in the text.

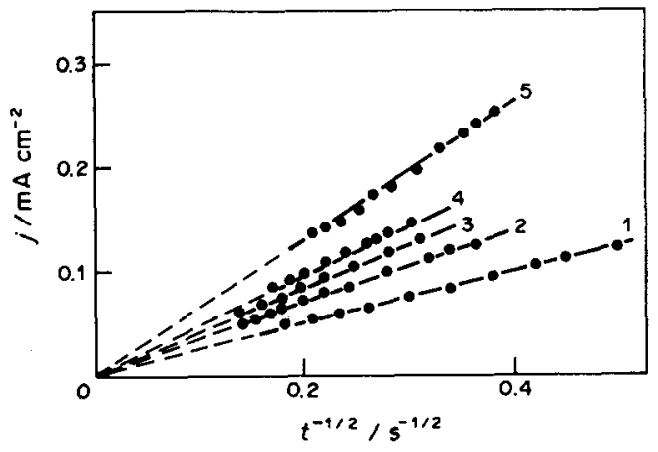

Fig. 5. Plots of $j$ vs $t^{-1 / 2}$ for $t \gg t_{M 1}$ from data shown in Fig. 4. $E_{\mathrm{s}}=(1) 0.140 ;$ (2) 0.135 ; (3) 0.130 ; (4) 0.125 ; (5) $0.120 \mathrm{~V} .25^{\circ} \mathrm{C}$. compared to those resulting for the reaction on single crystal silver electrodes $[25,26]$.

The SEM micrographs of the electroreduced silver layers exhibit two representative situations (Fig. 10). The silver layer made at $0.129 \mathrm{~V}$ consists of a large number of small rod-like crystals (Fig. 11a), but the one prepared at $E_{\mathrm{s}}=0.00 \mathrm{~V}$, consists of a large number of globular silver crystals similar to those earlier reported in the literature for other silver electrodeposits [8, 25]. The histograms (Fig. 11) resulting from SEM micrographs show that the crystal size range for $E_{\mathrm{s}}=0.129 \mathrm{~V}$ becomes broader than that obtained for $E_{\mathrm{s}}=0.00 \mathrm{~V}$. In the former case, the average crystal size is $280 \mathrm{~nm}$, whereas in the latter it is $170 \mathrm{~nm}$. 


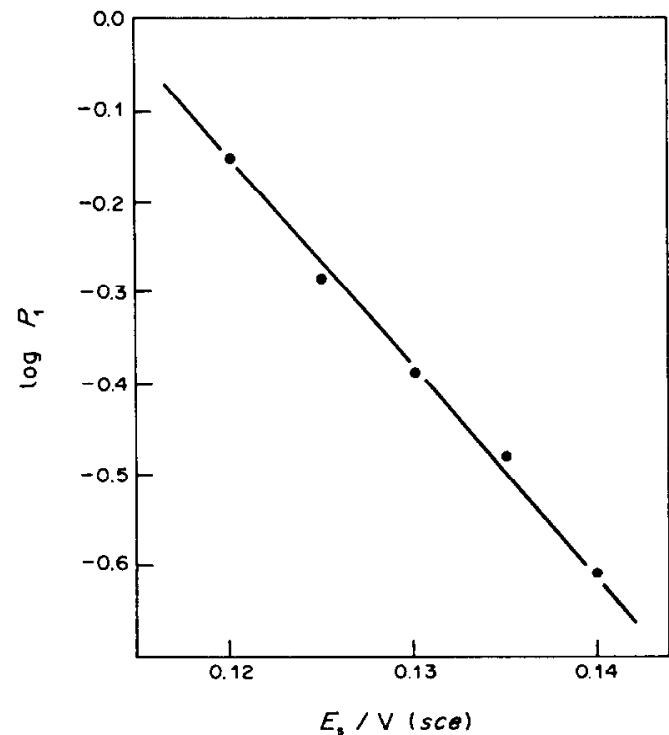

Fig. 6. Potential dependence of the slopes of the straightlines $(P)$ depicted in Fig. 5, plotted as $\log P$ vs $E_{\mathrm{s}}$.

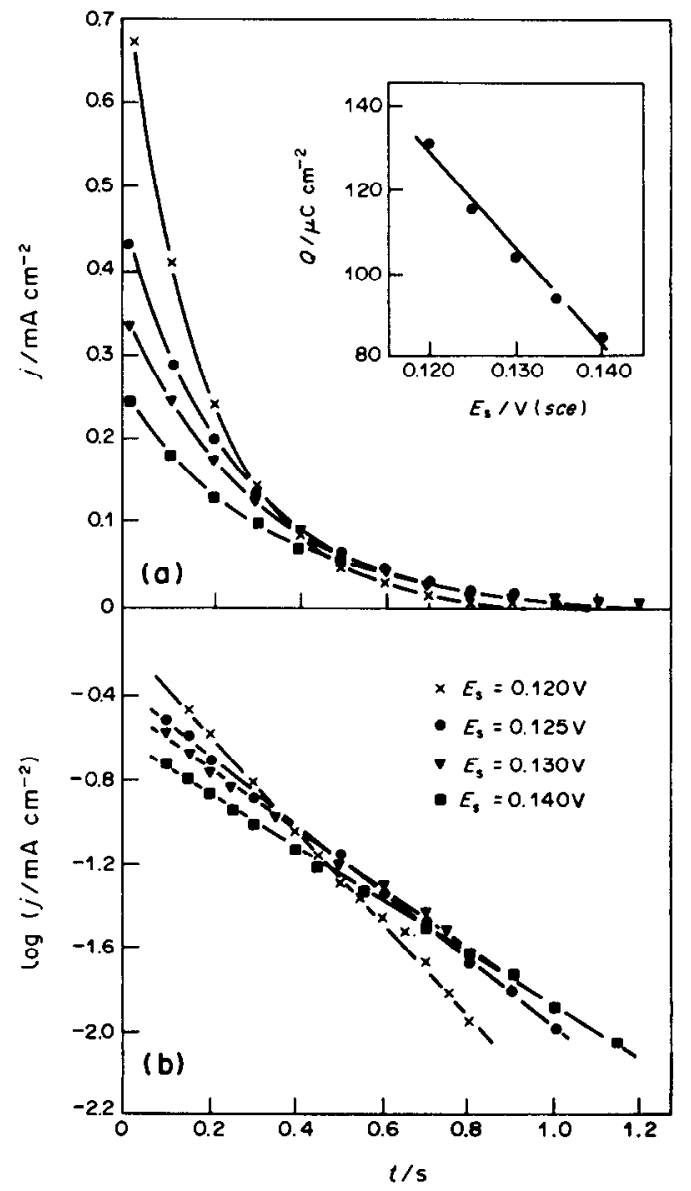

Fig. 7. (a) Initial cathodic current decays at different $E_{\mathrm{s}}$ after correction for the current related to process $R_{1}: E_{s}=0.125$; $0.120 \mathrm{~V}$. (b) $\log j$ vs $t$ plots of data depicted in Fig. $7 \mathrm{a}$.

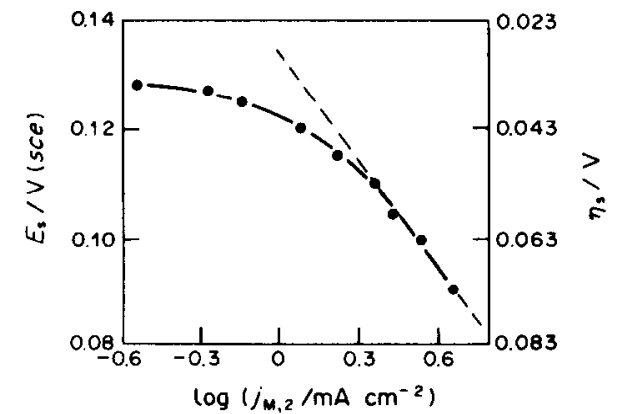

Fig. 8. $E_{\mathrm{s}} v s \log j_{M 2}$ plot for process $\mathbf{R}_{2}$. The definition of $\eta$ is given in the text.
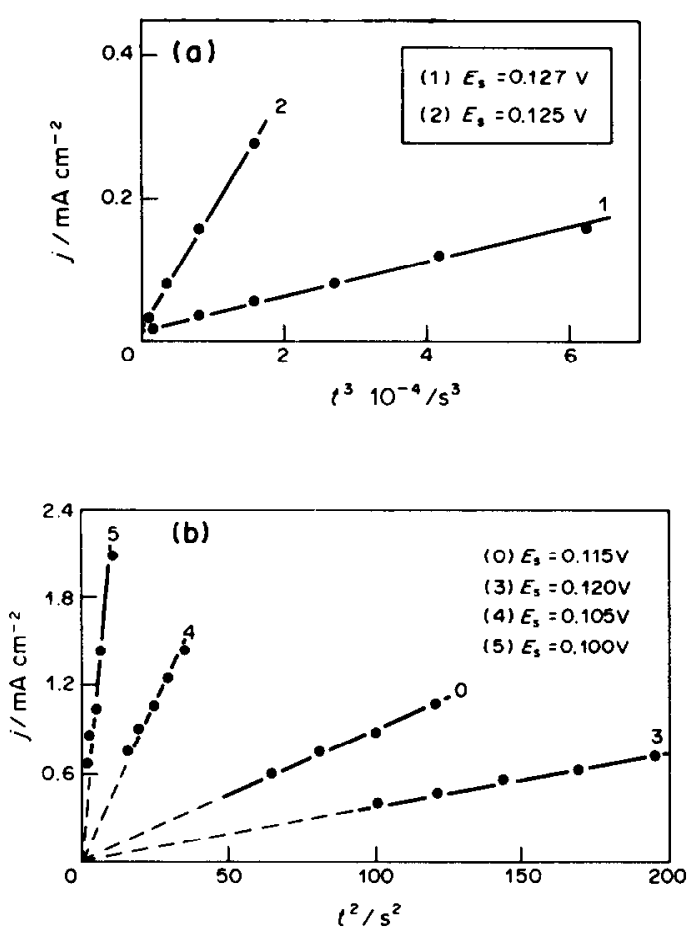

Fig. 9. (a) $j v s t^{3}$ and (b) $j v s t^{2}$ plots for the ascending portion of the cathodic current transient associated with process $\mathbf{R}_{\mathbf{2}}$.

The thallium UPD runs were made by employing conventional voltammetry between -0.2 and $0.75 \mathrm{~V}$ at $0.01 \mathrm{~V} \mathrm{~s}^{-1}$ with the working electrode immersed in $0.1 \mathrm{M} \mathrm{HClO}_{4}+10^{-3} \mathrm{M} \mathrm{TlSO}_{4}$. These results are comparatively depicted in Fig. 12 for (a) mirror polished pc silver, and silver layers produced on silver from $\mathrm{Ag}(\mathrm{I})$ oxide electroreduction at (b) $E_{\mathrm{s}}=0.129$, (c) 0.100 and (d) $0.00 \mathrm{~V}$. The voltammetric charge densities resulting for (b), (c) and (d) are approximately twice the charge density values obtained for (a). The assignment of the voltammetric peaks to the different crystalline faces as shown in Table 1, is based upon the most reliable results on the matter available at present $[21,26]$. The thallium UPD voltammograms resulting for the different silver layers tend to agree, in general, to those described for $\mathrm{Ag}(111)$ [26]. This fact is 
consistent with the predominance of $\mathrm{Ag}(111)$ crystalline faces for electroreduced $\mathrm{Ag}$ produced after a single oxidation-reduction cycle of a $\mathrm{Ag}$ electrode in $1 \mathrm{M}$ $\mathrm{KCl}$ as determined by X-ray diffractometry[21]. Nevertheless, the voltammetric response of thallium UPD on the electroreduced silver layers depends on $E_{\mathrm{s}}$ as observed for other systems[18]. This means that the silver layer topography becomes to some extent sensitive to $E_{\mathrm{s}}$, a fact which is reflected in the sharp conjugated pair of peaks $A_{4} / D_{4}$ and $A_{2} / D_{2}$ which can be clearly seen for $E_{s}=0.129 \mathrm{~V}$. The contributions of these pairs of peaks in the voltammogram decrease as $E_{\mathrm{s}}$ decreases.
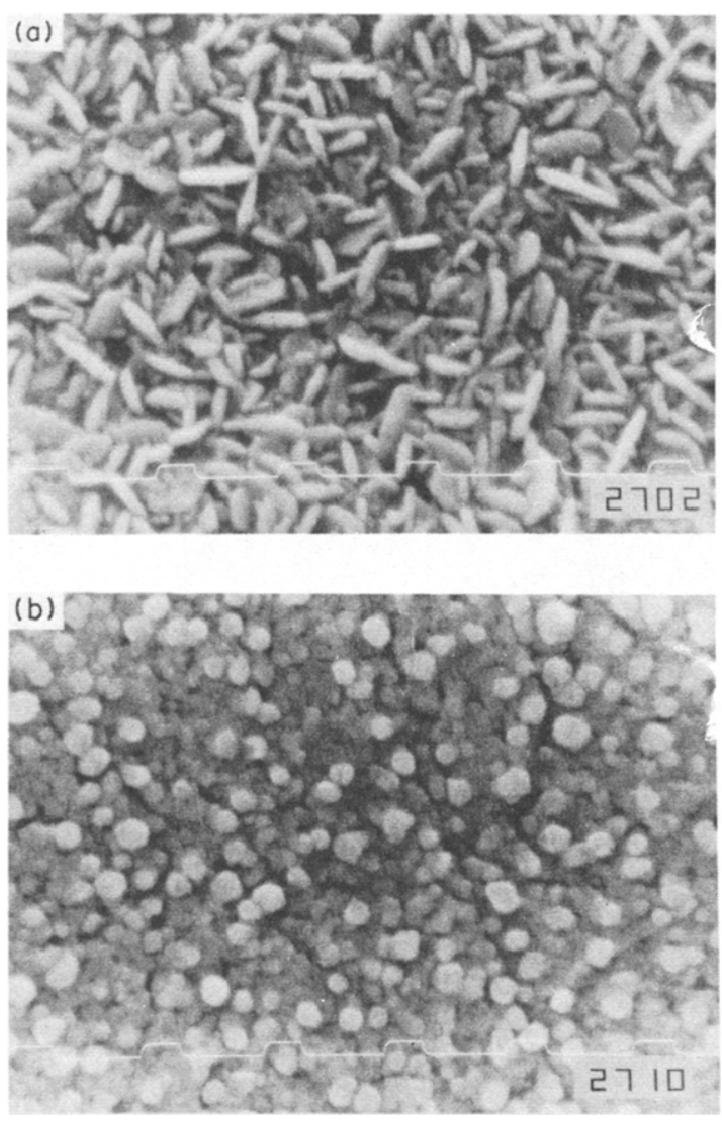

Fig. 10. SEM micrographs of electroreduced silver: (a) $E_{\mathrm{s}}=0.129 \mathrm{~V}$; (b) $0.00 \mathrm{~V}$.

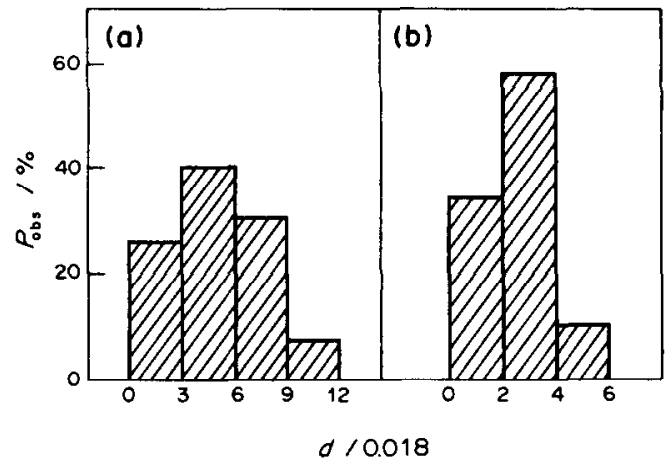

Fig. 11. Histograms calculated from SEM micrographs depicted in Fig. 10.

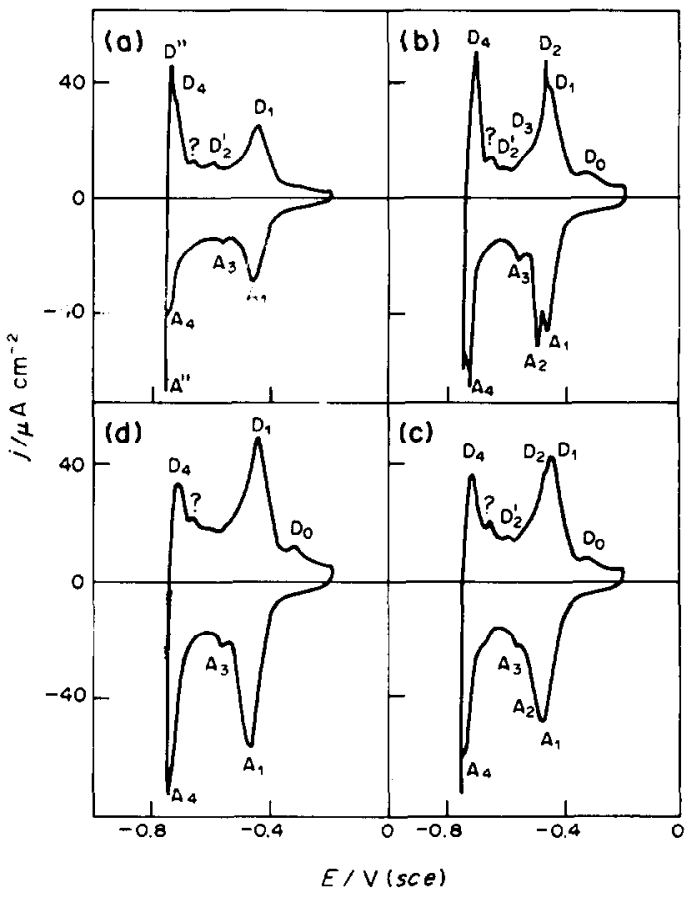

Fig. 12. Voltammograms for thallium UPD on silver electrodes run at $0.01 \mathrm{~V} \mathrm{~s}^{-1}$ between $E_{\mathrm{c}}=-0.20 \mathrm{~V}$ and $E_{\mathrm{a}}=0.75 \mathrm{~V}$, in $10^{-3} \mathrm{M} \mathrm{TlClO}_{4}+10^{-1} \mathrm{M} \mathrm{HClO}_{4} .25^{\circ} \mathrm{C}$. The silver electrodes were prepared through the potentiostatic electroreduction of $\mathrm{Ag}(\mathrm{I})$ oxide layers at different $E_{\mathrm{g}}$ : (a) mirror polished silver; (b) electroreduced silver at $E_{\text {s }}$ $=0.129 \mathrm{~V}$; (c) $E_{\mathrm{s}}=0.100 \mathrm{~V}$; (d) $E_{\mathrm{s}}=0.00 \mathrm{~V}$.

Table 1. Location of peak potentials for thallium UPD on silver electrodes at $0.01 \mathrm{~V} \mathrm{~s}^{-1}$. Data from the literature[21, 26] and from Fig. 11

\begin{tabular}{|c|c|c|c|c|c|c|c|}
\hline \multirow{2}{*}{\multicolumn{2}{|c|}{$\begin{array}{l}\text { Pair of peaks in } \\
\text { Ag single crystals }\end{array}$}} & \multirow{2}{*}{ Reference[26] } & \multirow[b]{2}{*}{ Reference[21] } & \multicolumn{2}{|c|}{ Peak potential/V(sce) } & \multirow[b]{2}{*}{ Figure 11c } & \multirow[b]{2}{*}{ Figure 11d } \\
\hline & & & & Figure 11a & Figure 11b & & \\
\hline $\operatorname{Ag}(111)$ & $\begin{array}{c}A_{1} / D_{1} \\
A_{2} / D_{2} \\
A_{3} / D_{3} \\
A_{4} / D_{4} \\
D_{0}\end{array}$ & $\begin{array}{c}-0.47 /-0.46 \\
-0.51 /-0.50 \\
-0.575 /-0.555 \\
-0.735 /-0.725 \\
-0.255\end{array}$ & $\begin{array}{c}-0.47 /-0.46 \\
-0.47 /-0.46 \\
-0.56 /-0.52 \\
-\end{array}$ & $\begin{array}{c}-0.465 /-0.445 \\
- \\
-0.56 /-0.52 \\
-0.74 /-0.72 \\
-\end{array}$ & $\begin{array}{c}-0.47 /-0.45 \\
-0.49 /-0.47 \\
-0.56 /-0.52 \\
-0.735 /-0.71 \\
-0.32\end{array}$ & $\begin{array}{c}-0.47 /-0.44 \\
-0.55 /-0.461 \\
-0.555 /-0.52 \\
-0.73 /-0.71 \\
-0.32\end{array}$ & $\begin{array}{c}-0.47 /-0.45 \\
- \\
-0.56 /-0.52 \\
-0.74 /-0.71 \\
-0.32\end{array}$ \\
\hline $\mathrm{Ag}(100)$ & $\begin{array}{l}\mathbf{A}_{1}^{\prime} / \mathbf{D}_{1}^{\prime} \\
\mathbf{A}_{2}^{\prime} / \mathbf{D}_{2}^{\prime} \\
\mathbf{A}_{3}^{\prime} / \mathbf{D}_{3}^{\prime}\end{array}$ & $\begin{array}{l}-0.46 /-0.445 \\
-0.60 /-0.595 \\
-0.73 /-0.72\end{array}$ & $\begin{array}{l}- \\
-\end{array}$ & $-0.600 /-0.595$ & $-0 . \overline{-} \overline{-}-0.59$ & $-0.60 /-0.585$ & $-0.060 /-0.590$ \\
\hline
\end{tabular}




\section{DISCUSSION}

The electroreduction of $\mathrm{Ag}(\mathrm{I})$ oxide layer shows up at least three distinguishable electroreduction stages through the behaviour of the current transients run at a constant potential. The number of stages correlates to the complex structure of the $\mathrm{Ag}(\mathrm{I})$ oxide layer which according to the literature[5] involves $\mathrm{a}_{\mathrm{Ag}_{2}} \mathrm{O}$ monolayer in contact with the metal ( $0.4 \mathrm{~nm}$ thick), a homogeneous primary layer[3], its thickness being in the order of $10 \mathrm{~nm}[12]$, and a thick secondary layer formed by globular crystals of $50-300 \mathrm{~nm}$ size[5] depending on the ageing time. The time window and the charge densities associated with each stage suggest that the electroreduction process undergoes successively, from the $\mathrm{Ag}_{2} \mathrm{O}$ monolayer to the secondary layer. The precedent analysis and interpretation of the results allows to discuss the kinetics and mechanism of each stage separately in the following paragraphs.

The likely mechanism of the $\mathrm{Ag}_{2} \mathrm{O}$ monolayer electroreduction

The initial falling current in the potentiostatic current transient, corrected for the electric double layer discharge, can be assigned to the electroreduction of the $\mathrm{Ag}_{2} \mathrm{O}$ monolayer in direct contact with the silver substrate. In this case, the time dependence of the current density, $j(t)$, is given by the expression:

$$
j(t)=P_{1} \exp \left(-P_{2} t\right)
$$

where $P_{1}$ and $P_{2}$ are constants to be interpreted via a model. The constant $P_{2}$ appears to be dependent on $E_{\mathrm{s}}$ (Fig. 7b). Thus, equation (1) can be related to an instantaneous nucleation and 2-D growth under diffusion control[27]. In this case $P_{1}$ and $P_{2}$ are explicitly given by the following equations:

$$
\begin{aligned}
& P_{1}=\pi K_{\mathrm{e}} D N_{\mathrm{o}} \\
& P_{2}=q_{\mathrm{m}} \pi K_{\mathrm{e}} D N_{\mathrm{o}}
\end{aligned}
$$

where $K_{\mathrm{e}}$ denotes a proportionality constant, $D$ is the diffusion coefficient of the species involved in the process, $N_{\mathrm{o}}$ is the number density of active sites and $q_{\mathrm{m}}$ is the monolayer charge density.

On the other hand, equation (1) can be also assigned to an adsorption process [28] although in this case the meanings of the $P_{1}$ and $P_{2}$ are obviously different. Unfortunately, at present it is not possible to decide between these reaction models exclusively on the basis of the fulfillment of equation (1) at the initiation of current transient under constant potential.

\section{The mechanism of the primary layer electroreduction}

The shape of the current transients after the initial falling current resembles that described for an instantaneous nucleation and 3-D growth mechanism involving either hemispherical or conical silver nuclei growth under ionic diffusion rate control through the secondary layer. For this model the corresponding equation for $j(t)$ is[29]:

$$
j_{1}(t)=\frac{P_{3}}{\sqrt{ } t}\left[1-\exp \left(-P_{4} t\right)\right]+\frac{P_{4}}{P_{5}}\left[1-\exp \left(-P_{5} t\right)\right],
$$

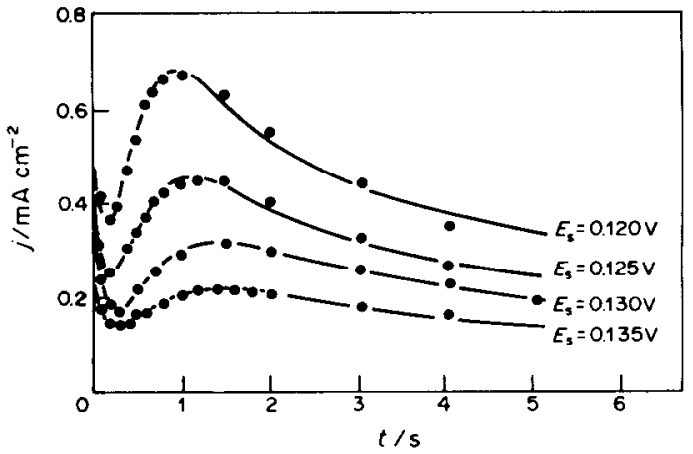

Fig. 13. Fitting of current transient data according to equation (8) (full traces) with parameters assembled in Table 2.

where:

$$
\begin{aligned}
& P_{3}=\frac{z \mathrm{~F} D^{1 / 2} c_{\mathrm{o}}}{\pi^{1 / 2}}, \\
& P_{4}=\pi K_{2} D N_{\mathrm{o}} \\
& P_{5}=\alpha,
\end{aligned}
$$

$c_{\mathrm{o}}$ is the concentration of the diffusing particles in the silver oxide phase at the reaction plane, and $\alpha$ is the nucleation rate constant. Hence, the entire current transients, $j(t)$, related to the electroreduction of both the $\mathrm{Ag}_{2} \mathrm{O}$ monolayer and the primary layer should obey the following equation:

$$
\begin{aligned}
j(t)= & P_{1} \exp \left(-P_{2} t\right)+\frac{P_{3}}{\sqrt{ } t}\left[1-\exp \left(-P_{4} t\right)\right] \\
& +\frac{P_{4}}{P_{5}}\left[1-\exp \left(-P_{5} t\right)\right] .
\end{aligned}
$$

The current-time transients, as depicted in Fig. 4, can be satisfactorily reproduced (Fig. 13) through equation (8) by using the parameters assembled in Table 2. It is instructive to derive a coherent physical picture about the electroreduction process from the values of the parameters given in Table 2 .

Thus, the validity of the nucleation and growth model implies that the $P_{1} / P_{2}$ ratio be related to the electroreduction charge density of the $\mathrm{Ag}_{2} \mathrm{O}$ monolayer. However, the resulting values of $q_{m}$ are lower than those expected for an epitaxial $\mathrm{O}$-containing monolayer on the basis of a $\mathrm{Ag} / \mathrm{O}$ atom ratio equal to 2 , and in addition it increases as $E_{\mathrm{s}}$ is set more negatively (Fig. 7a); it changes from $0.085 \mathrm{mC} \mathrm{cm}^{-2}$ for $E_{\mathrm{s}}=0.140 \mathrm{~V}$ to $0.135 \mathrm{mC} \mathrm{cm}^{-2}$ for $E_{\mathrm{s}}=0.12 \mathrm{~V}$. This difference can be taken as an indication that the complete electroreduction of the $\mathrm{Ag}_{2} \mathrm{O}$ monolayer is only achieved at the most negative $E_{\mathrm{s}}$ values.

For other parameters containing information about the electroreduction of the primary layer, let us consider the value of $\boldsymbol{P}_{3}$ which increases as $\boldsymbol{F}_{\mathrm{s}}$ decreases, a fact which cannot be expected for a simple diffusional process, but which can be tentatively attributed to a dependence of $c_{\mathrm{o}}$ on $E_{\mathrm{s}}$, and perhaps to a minor extent, to a change of $D$ with $E_{s}$. Let us consider the overall reaction involved in the $\mathrm{Ag}(\mathrm{I})$ oxide layer electrore- 
Table 2. Parameters employed to fit experimental data according to equation (8) as depicted in Fig. 12

\begin{tabular}{ccccccc}
\hline$E_{3} / \mathrm{V}$ & $P_{1} / \mathrm{mA} \mathrm{cm}^{-2}$ & $P_{2} / \mathrm{s}^{-1}$ & $P_{3} / \mathrm{mA} \mathrm{s}^{1 / 2} \mathrm{~cm}^{-2}$ & $P_{4} / s^{-1}$ & $P_{5} / \mathrm{s}^{-1}$ & $P_{4} P_{5} / \mathrm{s}^{-2}$ \\
\hline 0.135 & 0.25 & 4.4 & 0.31 & 1.6 & 2.5 & 4.1 \\
0.130 & 0.37 & 5.4 & 0.43 & 2.5 & 1.4 & 3.6 \\
0.125 & 0.49 & 6.0 & 0.54 & 4.0 & 1.3 & 5.1 \\
0.120 & 0.67 & 6.8 & 0.74 & 5.8 & 1.1 & 6.4 \\
\hline
\end{tabular}

duction:

$$
\begin{gathered}
\mathrm{Ag}_{2} \mathrm{O}+\mathrm{H}_{2} \mathrm{O}+2 \mathrm{e}^{-} \Leftrightarrow \mathrm{Ag}^{\circ}+2 \mathrm{OH}^{-} \\
E_{\mathbf{r}}(0.1 \mathrm{M} \mathrm{NaOH}) / v s s c e=0.16 \mathrm{~V} .
\end{gathered}
$$

Reaction (9) implies a phase change which can be described as a nucleation and 3-D growth under diffusion control, probably involving $\mathrm{OH}^{-}$ions through the $\operatorname{Ag}(\mathbf{I})$ oxide layer. For such a case, provided that reaction (9) is a fast electron transfer reaction, the concentration of $\mathrm{OH}^{-}$ions at the metal-oxide interface should depend on $E_{s}$. Thereby, $c_{0}$ should increase and the tails of the current transients become greater as $E_{\mathbf{s}}$ is set more negatively.

On the other hand, a dependence of $P_{4}$ on $E_{s}$ (see Table 2) can be related to an increase in the value of $N_{\text {o }}$ produced through a change in $K_{\mathrm{e}}$ due to the increase of $c_{0}$. However, this can only explain a change in $P_{4}$ by a factor of about 2, a figure smaller than the factor of about 5 as seen from data assembled in Table 2. Finally, it is not easy to account for the slight decrease in $\alpha$ as $E_{\mathrm{s}}$ is set more negatively. It means that the rate of conversion of an active site into a silver nuclei decreases slightly as the overpotential, $\eta$, defined as $\eta=E_{\mathrm{r}}-E_{\mathrm{s}}$, increases.

Nevertheless, a tentative explanation of the opposite dependences of $P_{4}$ and $P_{5}$ on $E_{\mathrm{s}}$ can be advanced in terms of a change in the surface active area related to the electroreduction process itself. It is known that the electrocrystallization of silver can be accomplished with a different degree of roughness according to the electroreduction potential value[30]. Otherwise, both $P_{4}$ and $P_{5}$ are kinetic parameters exclusively related to the electrochemical surface process, probably controlled by a chemical step. An increase in roughness involves an increase of the surface to volume ratio of the growing units, a fact which quite likely implies drastic changes in $N_{0}$, most probably an increase of $N_{0}$ according to $E_{\mathrm{s}}$. On the other hand, if one admits that the active site to nucleus conversion behaves as an equilibrium process, it is reasonable to expect that an increase in $N_{\mathrm{o}}$ produces a decrease in $P_{5}$, ie in the value of $\alpha$. Furthermore, it should be noted that the stationary nucleation rate, $I_{\mathrm{st}}$, is given by the expression:

$$
I_{\mathrm{st}}=\alpha N_{\mathrm{o}}
$$

so that the fact that $I_{\mathrm{st}}$ appears to be rather slightly sensitive to $E_{\mathrm{s}}$ agrees with a counterbalanced dependence of $N_{\mathrm{o}}$ and $\alpha$ on $E_{\mathrm{s}}$. This interpretation, however is not conclusive and other possibilities have to be explored to account for the electroreduction of the primary layer based on further experimental data.
The likely mechanism for the secondary layer electroreduction

The phenomenological relationships derived from the potentiostatic current transients for process $R_{2}$, exceed also the prediction of a simple nucleation and 3-D growth model under charge transfer control[31], that is, the current transients show no asymptotic current values for $t \rightarrow \infty$. In constrast, they exhibit a rapid fall of current when $t>t_{\mathrm{M} 2}$, and it approaches zero for $t \Rightarrow \infty$. Furthermore, for a nucleation and 3-D model under diffusion control the initial rising part of the current transient should obey linear either $j v s t^{1 / 2}$ or $j v s t^{3 / 2}$ plots and the falling part should approach a linear $j$ vs $t^{-1 / 2}$ plot (Fig. 5) [32]. The experimental data are far from these expectations as the rising part of the current transients fit a reasonable linear dependence on either $t^{2}$ or $t^{3}$ (Fig. 9), according to the value of $E_{s}$. Therefore, it seems unlikely that the electroreduction of the secondary layer could be described by any one of those simple models.

Let us consider as a possible description of the process in terms of the nucleation and 3-D either hemispherical or conical growth model under charge transfer control involving the surface diffusion of adatoms (as has been originally proposed to explain the electroformation of a passive layer on several metals[33]), but including a death term for either the growing or the disappearing phase centers as the electroreduction process proceeds. In this case, the current decay equations under constant potential conditions become:

$$
j(t)=P_{6}\left[1-\exp \left(-P_{7} t^{2}\right)\right] \exp \left(-P_{7} t^{2}\right),
$$

for instantaneous nucleation, and:

$$
j(t)=P_{6}\left[1-\exp \left(-P_{8} t^{3}\right)\right] \exp \left(-P_{8} t^{3}\right),
$$

for progressive nucleation. In these equations, the parameters $P_{6}, P_{7}$ and $P_{8}$, can be directly estimated from the experimental data (Table 3), ie $j_{\mathrm{M} 2}$, and $t_{\mathrm{M} 2}$, and from the parametric functionalities of the model. The latter as well as the definitions of $P_{6}, P_{7}$ and $P_{8}$ are given in Table 4.

For a comparison between the predictions of the model and the experimental results shown in Fig. 4, the current transients were previously corrected to eliminate the contribution of process $R_{1}$. The theoretical calculations were made by using the parameters assembled in Table 3. From the curve fitting as presented in Fig. 14 it appears that for $E_{\mathrm{s}}>0.125 \mathrm{~V}$, the process $\mathbf{R}_{\mathbf{2}}$ is better described in terms of a progressive nucleation, whereas for $E_{s} \leq 0.10 \mathrm{~V}$ an instantaneous nucleation appears to be more appropriate. These conclusions agree with the type of surface topography 
Table 3. Adjusting parameters used in equations (11) and (12)

\begin{tabular}{|c|c|c|c|c|c|c|}
\hline$E_{\mathrm{s}} / \mathrm{V}$ & $j_{\mathrm{M} 2} / \mathrm{A} \mathrm{cm}^{-2}$ & $t_{\mathrm{M} 2} / \mathrm{s}$ & $P_{6} / \mathrm{A} \mathrm{cm}^{-2}$ & $P_{7} / \mathbf{s}^{-\mathbf{a}}$ & $P_{6} / \mathrm{A} \mathrm{cm}^{-2}$ & $P_{8} / s^{-2}$ \\
\hline \multicolumn{7}{|c|}{ Instantaneous nucleation } \\
\hline 0.127 & $0.56 \times 10^{-3}$ & 66.0 & $2.24 \times 10^{-3}$ & $2.41 \times 10^{-3}$ & & \\
\hline 0.125 & $0.75 \times 10^{-3}$ & 49.8 & $3.01 \times 10^{-3}$ & $5.61 \times 10^{-6}$ & & \\
\hline \multicolumn{7}{|c|}{ Progressive nucleation } \\
\hline 0.120 & $1.23 \times 10^{-3}$ & 25.2 & & & $4.92 \times 10^{-3}$ & $1.09 \times 10^{-3}$ \\
\hline 0.105 & $2.60 \times 10^{-3}$ & 12.0 & & & $1.04 \times 10^{-2}$ & $4.82 \times 10^{-3}$ \\
\hline 0.100 & $3.59 \times 10^{-3}$ & 7.5 & & & $1.44 \times 10^{-2}$ & $1.23 \times 10^{-2}$ \\
\hline
\end{tabular}

Table 4. Parametric functionalities resulting for the nucleation and conical 3-D growth models under charge transfer control including a death term for nuclei growth. Adapted from [33]

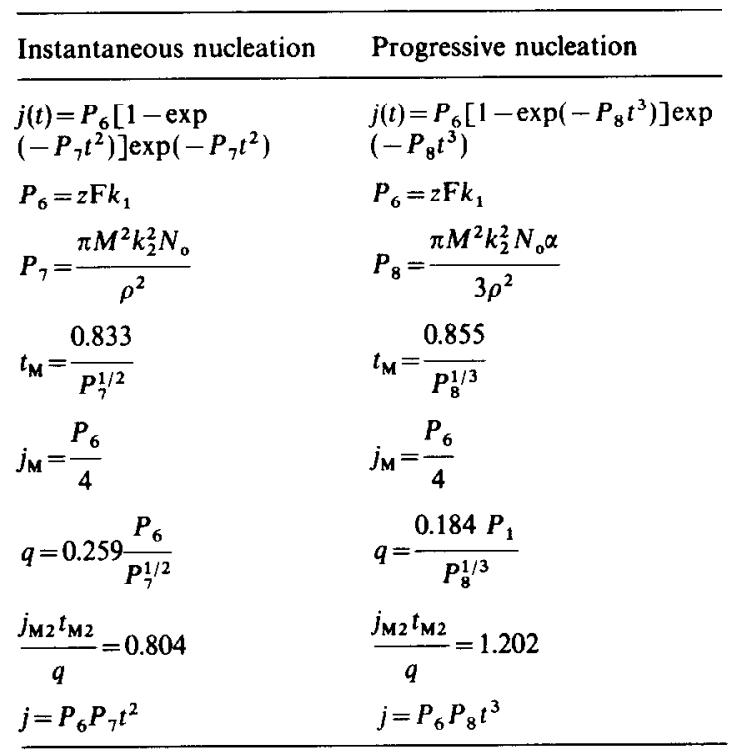

$k_{1}=$ perpendicular growth rate constant; $k_{2}=$ parallel growth rate constant; $M=$ molecular weight; $N_{0}=$ number of active sites per $\mathrm{cm}^{2} ; \rho=$ specific gravity; $\alpha=$ nucleation rate constant.

of the resulting silver layer as seen through SEM micrographs (Fig. 10), although the conclusions from the corresponding histograms must be handled cautiously due to possible interferences of surface reconstruction and sintering effects[18] due to the relatively large time involved in obtaining the SEM micrographs.

On the other hand, it should be noted that the dependence of $P_{6}$, the perpendicular growth rate constant, on $E_{5}$, expressed as dlog $P_{6} / \mathrm{d} E_{\mathrm{s}}$, is close to $0.030 \mathrm{~V} \mathrm{dec}^{-1}$, a value which is consistent with charge transfer control for process $R_{2}$ as implied in the model.

It is surprising that despite the fact that both processes $R_{1}$ and $R_{2}$ involve a common phase change with the participation of water molecules and $\mathrm{OH}^{-}$ ions, the diffusion kinetic control only appears for process $R_{1}$ and is not observable for process $R_{2}$. This difference can be accounted for by considering the

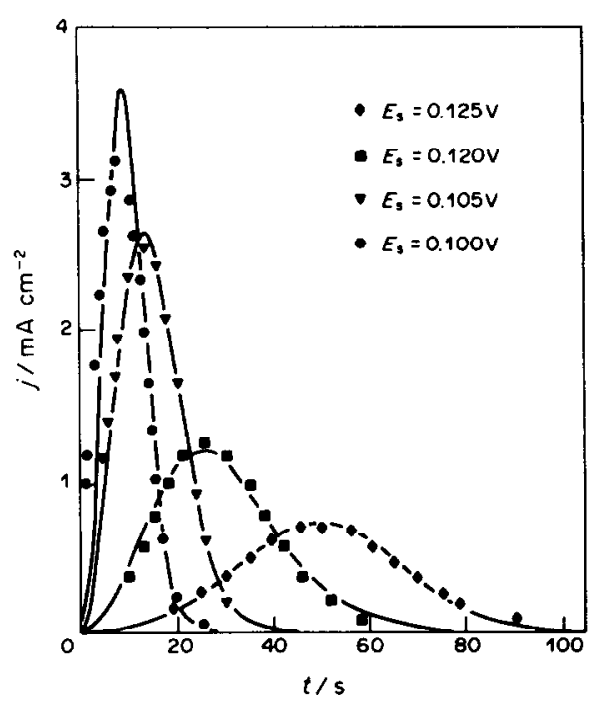

Fig. 14. Fitting of current transient data for process $\mathbf{R}_{\mathbf{2}}$ according to equations (11) and (12) (full traces) with parameters assembled in Table 3.

differences between the water content and the degree of porosity of the primary and secondary layers. Previously reported data[2-5] indicate that the porosity and the water content of the secondary layer are greater than those of the primary layer. Furthermore, these facts can explain the voltammetric relationships earlier reported, that is, the linear $j_{\mathrm{p}} v s v$ and the linear $j_{\mathrm{p}}$ vs $v^{1 / 2}$ dependences, for $v \Rightarrow 0$ and $v \Rightarrow \infty$, respectively[16]. The former relationship is consistent with a nucleation and growth process under charge transfer control, whereas the latter is in agreement with the predictions of a nucleation and growth process under diffusion control.

Finally, the facts that the structure and electrochemical properties of the resulting silver layers be dependent on the electroreduction conditions is not surprising as this type of behaviour has also been recently described for platinum[34] and gold layers $[18,35]$ resulting from the electroreduction of the corresponding thick metal oxide layers. In this sense, the same type of behaviour is fulfilled by the electroreduction of silver oxide layer to silver. 


\section{CONCLUSIONS}

(1) The electroreduction of $\mathrm{Ag}(\mathrm{I})$ oxide layers involves three distinguishable processes comprising as successive reactants the $\mathrm{Ag}_{2} \mathrm{O}$ monolayer, the primary more compact $A g(I)$ oxide layer and the secondary more hydrous and porous $\mathrm{Ag}(\mathrm{I})$ oxide layer. The time scale of each process allowed to investigate them separately, at least with a minimum overlapping. This fact facilitates a reasonable deconvolution of the complex potentiostatic electroreduction current transients.

(2) The electroreduction of the $\mathrm{Ag}_{2} \mathrm{O}$ monolayer follows a first order kinetics, $i e$ an exponential decay law. The electroreduction of the primary layer can be described as a nucleation and 3-D growth mechanism under $\mathrm{OH}^{-}$ion diffusion control through the silver oxide layer, involving either hemispherical or conical growing centers. The secondary layer also follows a nucleation and growth mechanism under charge transfer rate control. According to the electroreduction potential step value, either an instantaneous of a progressive nucleation is likely involved in the electroreduction of the secondary layer.

(3) SEM micrographs reveal two limiting topographies for the reduced silver layer. The latter involves the development of roughness and a net (111)type preferred crystalline orientation. SEM results, in principle, correlate satisfactorily with the conclusions derived from the electrochemical data.

(4) Results from the analysis of potentiostatic electroreduction current transients and those from the theoretical model can explain the limiting voltammetric electroreduction current peak height $v$ s potential sweep rate relationships previously reported.

Acknowledgement-This research project was financially supported by the Consejo Nacional de Investigaciones Cientificas y Técnicas and the Comisión de Investigaciones Científicas de la Provincia de Buenos Aires. This work was partially supported by the Regional Program for the Scientific and Technological Development of the Organization of the American States.

\section{REFERENCES}

1. J. M. M. Drogg, J. electroanal. Chem. 115, 225 (1980).

2. J. Zerbino, M. López Teijelo, J. R. Vilche and A. J. Arvia, Electrochim. Acta 30, 1521 (1985).

3. J. Gómez Becerra, R. C. Salvarezza and A. J. Arvia, Electrochim. Acta 33, 1431 (1988).

4. C. Alonso, R. C. Salvarezza, J. Vara and A. J. Arvia, Electrochim. Acta 35, 489 (1990).
5. S. Meyer and R. Muller, J. electrochem. Soc. 135, 2133 (1988).

6. M. López Teijelo, J. R. Vilche and A. J. Arvia, J. electroanal. Chem. 131, 331 (1982).

7. P. Stonehart, Electrochim. Acta 13, 1789 (1968).

8. B. V. Zelak, R. S. Perkins, H. A. Kozlowska and J. E. Conway, Electrochim. Acta 17, 1447 (1972).

9. B. G. Pound, D. D. Mac Donald and J. Tomlenson, Electrochim. Acta 25, 563 (1980).

10. M. Fleischmann and H. P. Thirsk, in Advances in Electrochemistry and Electrochemical Engineering (Edited by P. Delahay)、 Vol. 3, p. 123, Interscience, New York (1961).

11. M. Fleischmann, D. J. Lax and H. P. Thirsk, Trans. Faraday Soc. 64, 3128 (1968).

12. G. W. D. Briggs, M. Fleischmann, D. J. Lax and H. P. Thirsk, Trans. Faraday Soc. 64, 3120 (1968).

13. A. N. Kolmogoroff, Bull. Acad. Sci. S.S.S.R. 3, 335 (1937).

14. M. Avrami, J. chem. Phys. 7, 1103 (1939); J. chem. Phys. 8, 212 (1940); J. chem. Phys. 9, 177 (1941).

15. J. M. M. Drogg and F. Huismansm, J. electroanal. Chem. 115, 211 (1980).

16. M. López Teijelo, J. R. Vilche and A. J. Arvia, J. electroanal. Chem. 162, 207 (1984).

17. R. Schumacher, J. G. Gordon and O. Melroy, J. electroanal. Chem. 216, 127 (1987).

18. L. Vázquez, A. Bartolomé, A. M. Baró, C. Alonso, R. C. Salvarezza and A. J. Arvia, Surf. Sci. 215, 171 (1989).

19. C. Alonso, L. Vázquez, R. C. Salvarezza, A. M. Baró, J. Vara and A. J. Arvia, J. electrochem. Soc., in press.

20. R. Schumacher, G. Borges and K. K. Kanazawa, Surf. Sci. 163, 1621 (1985).

21. M. Fleischmann and B. W. Mao, J. electroanal. Chem. 247, 297 (1988).

22. M. L. A. Temperini, D. Sala, G. I. Lacconi, A. S. Gioda, V. A. Macagno and A. J. Arvia, Langmuir 4, 1032 (1988).

23. M. H. J. Hottenhuis, A. L. M. van den Berg and J. P. van der Erden, Electrochim. Acta 33, 1519 (1988).

24. R. C. Salvarezza, J. Gomez Becerra and A. J. Arvia, Electrochim. Acta 33, 1753 (1988).

25. K. Juttner, Electrochim. Acta 31, 917 (1986).

26. H. Siegenthaler, K. Juttner, E. Schmidt and W. J. Lorenz, Electrochim. Acta 23, 1009 (1978).

27. W. Davison and J. A. Harrison, J. electroanal. Chem. 44, 213 (1973).

28. R. G. Barradas and E. Bosco, J. electroanal. Chem. 193, 23 (1985).

29. B. Scharifker and J. Mostany, J. electroanal. Chem. 177. 13 (1984).

30. M. E. Vela, R. C. Salvarezza and A. J. Arvia, in preparation.

31. M. Y. Abyaneh and M. Fleischmann, Electrochim. Acta 27, 1513 (1982).

32. B. Scharifker and G. Hill, Electrochim. Acta 28, 879 (1983).

33. R. D. Armstrong, M. Fleischmann and H. R. Thirsk, $J$. electroanal. Chem. 31, 917 (1966).

34. A. E. Bolzan, A. M. Castro Luna, A. Visintin, R. C. Salvarezza and A. J. Arvia, Electrochim. Acta 33, 1743 (1988).

35. M. E. Vela, R. C. Salvarezza and A. J. Arvia, Electrochim Acta 35, 117 (1990). 